\title{
Responding to Gender-based Violence in Disasters: Grappling With Research Methods to Clear the Way for Planning
}

Stephanie Rosborough, MD, MPH, Jennifer L. Chan, MD, MPH, and Parveen Parmar, MD

$\mathrm{D}$ isasters have particularly devastating effects on vulnerable populations, especially women, children, and older adults. Prioritization of these groups in disaster response plans is crucial. Yet many of the ways in which vulnerable groups are affected by disaster remain invisible to the public health and disaster communities.

In this issue of Disaster Medicine and Public Health Preparedness, Anastario et $\mathrm{al}^{1}$ bring to light a vulnerability that is often hidden. Using sequential cross-sectional randomized surveys of trailer parks in Mississippi that were home to individuals displaced by Hurricane Katrina, Anastario et al documented a quantitative increase in gender-based violence (GBV) among a population living in protracted displacement after disaster. Among the population surveyed, the crude rate of GBV increased from 4.6 to $16.3 / 100,000$ per day after the hurricane and remained elevated at 10.1/100,000 per day in 2007. The majority of this sustained increase in GBV was due to intimate partner violence (IPV).

Disasters lead to increased stress on families and the destruction of social support networks. These stressors have been shown to lead to increased rates of child abuse; ${ }^{2,3}$ however, the effects of disaster on violence against women has been difficult to characterize. The literature on GBV in disasters to date mainly describes the effect of war on rates of sexual assault on women in the context of rape as a tool of war. ${ }^{4-6}$ Many also have highlighted the need for gender sensitivity in the physical layout and security of refugee camps to prevent violence against women in displaced populations. ${ }^{7-11}$

Relatively few authors have tackled GBV perpetrated by intimate partners in the context of disasters. Frasier et al surveyed blue collar women in North Carolina after Hurricane Floyd in 1999 on rates of IPV before and after the event. No definite increase was shown; however, there was a $32 \%$ nonresponse rate to the question about IPV.12 A survey of 2500 homes in Jordanian refugee camps showed a high lifetime prevalence of GBV, ${ }^{13}$ but did not specifically address how displacement had affected rates of violence against women. Closer to home, evidence exists that domestic violence shelters and call centers in the United States and
Canada experience increased demand after disasters, and have decreased access to resources needed to meet this demand. ${ }^{14}$ Sadly, it has been difficult to document the extent to which IPV and GBV increase after disasters, and the specific factors that lead to this increased vulnerability. Thus, Anastario et al have made a crucial step in providing one of the first studies to quantify the ongoing effects of disaster and displacement on rates of GBV.

Without a doubt, GBV, including IPV, is a particularly difficult topic to study. Humanitarian emergency and disaster researchers have struggled to characterize GBV through population-based studies using quantitative methods. Methodological challenges of this research include difficulty in accurately capturing an individual's GBV experience, inconsistent definitions of GBV, lack of accurate baseline GBV information, and translation of findings from qualitative or descriptive GBV studies into population-based studies.

Accurately reporting GBV depends not only upon an individual's ability to recognize a complex experience as GBV, but also one's willingness to report it. GBV is inherently linked to complex social environments, limiting the utility of traditional tools of disease measurement. The process of recalling and reporting a traumatic experience, coupled with the potential stigma associated with GBV, can contribute to underreporting and low response rates. Many studies in disaster and stable settings have shown nonresponse rates to vary widely. ${ }^{12,15-17}$ These variations not only affect the inherent validity of studies but also limit decision makers and provide unreliable baseline estimates.

Inconsistent GBV definitions can lead to misclassification, especially in a cross-cultural setting. Even residents within the same country can describe their experiences differently. GBV studies in stable settings have used a myriad of terms over different time periods including "physical violence," "emotional violence," "sexual violence," "intimate partner violence," and "sexual gender-based violence" (SGBV). In addition, terms reference different time periods, such as "lifetime IPV" and "postdisaster SGBV." These inconsistent terms result in wide prevalence estimates limiting comparison between studies. ${ }^{16-18}$ 
Further complicating GBV research is the frequent lack of baseline prevalence or incidence statistics in disaster-affected populations. ${ }^{15}$ The best proxy estimates for GBV are often aggregate statistics in stable settings. For example, the World Health Organization Multicountry Study on Women's Health and Domestic Violence Against Women studied women in 10 countries, intentionally selecting those who were not considered vulnerable to achieve more generalizable findings. ${ }^{15}$

The problem with these statistics is that they are often underestimates of the population under study. Communities affected by Hurricanes Katrina and Rita had a higher prevalence of vulnerability than the general population. A population-based survey of American Red Cross evacuees by Greenough et al $^{19}$ suggested that Katrina-affected populations came from vulnerable communities with low employment and lack of access to health care. It is also known that some of these vulnerabilities, such as poverty, are associated with IPV. Therefore, an ideal but often unrealistic baseline statistic would be prevalence/incidence of IPV among Katrina/Rita-affected communities. Alternative options would be regional or state estimates.

Despite these obstacles, researchers often use proxy statistics to power analysis. In this study, Anastario et $\mathrm{al}^{1}$ used major depressive disorder as a proxy for GBV followed by a post hoc power analysis. It is unclear why the study researchers did not use former aggregate GBV statistics from the 1996 National Violence Against Women Survey, the Louisiana 2006 IPV statistics from the Behavioral Risk Factor Surveillance System, or even the Mississippi and Louisiana state crime statistics for partner violence used in the first paper published from this dataset. ${ }^{20-23}$

Translating the body of GBV knowledge acquired from qualitative studies into population-based GBV studies is still a work in progress. Descriptive studies and qualitative methods have captured rich information on GBV by looking to respondents who self-present or by bringing individuals together to create an environment more hospitable for information sharing. The results from these studies inform important action-based research and provide indispensable information for programming. Unfortunately, these findings are inherently biased and limited to specific populations. The single interviewer-respondent relationship used in population-based studies can maintain privacy, but may lack the ideal environment for information sharing seen in qualitative studies. Current GBV definitions that are often inflexible in traditional population-based surveys may lead to misclassification if not thoroughly defined before the study.

Given that GBV is an emerging area in disaster planning and research, one way to resolve these challenging obstacles may be to consider combining the strengths of qualitative and quantitative population-based research. An amalgamation of these 2 well-developed methodologies may capture the specificity gained by qualitative studies while maintaining the statistical rigor and generalizability of population-based methods.

In addition, new sampling methodologies have emerged to attempt to measure hard to reach populations in complex social settings. Snowball and respondent-driven sampling take into account social networks as the thread of respondent identification and have merits in minimizing nonresponse and underreporting. Unfortunately, snowball sampling is limited by sampling bias, but the respondent-driven sampling method achieves probability sampling with less bias.

In short, the methodological challenges of GBV and IPV research in disasters are formidable. These challenges continue to limit the data available for accurate planning of the mental health response to an important and frequently overlooked outcome of disasters, particularly domestic and natural disasters. Innovative methods and continued study of postdisaster GBV is needed to properly inform disaster response.

Anastario et al further demonstrate that ongoing support for GBV programming in displaced communities is important not only in the immediate postdisaster phase but also well into the future. Indeed, this study indicates that the need for services may continue to rise even as memory of the disaster fades. Policymakers and mental health agencies should prepare for this increase.

Disaster response plans must therefore include robust, ongoing resources and funding for GBV services. To neglect this planning risks ignoring the most enduring ramifications of disasters. After all, jobs, houses, and possessions are replaceable, but psychological and emotional damage from disasters can last a lifetime.

\section{About the Authors}

Dr Rosborough is Director, International Emergency Medicine Fellowship, Department of Emergency Medicine, Brigham and Women's Hospital; Dr Chan is Assistant Professor, Section of Emergency Medicine, University of Chicago Medical Center; and Dr Parmar is International Emergency Medicine Fellow, Department of Emergency Medicine, Brigham and Women's Hospital.

Address correspondence and reprint requests to Dr Stephanie Rosborough, Dept of Emergency Medicine, Brigham and Women's Hospital, 75 Francis St, Boston, MA 02115 (e-mail: srosborough@partners.org).

Received for publication December 1, 2008; accepted December 2, 2008.

\section{Authors' Disclosures}

The authors report no conflicts of interest.

ISSN: 1935-7893 C 2009 by the American Medical Association and Lippincott Williams \& Wilkins.

DOI: 10.1097/DMP.0b013e31819738f9

\section{REFERENCES}

1. Anastario M, Shehab N, Lawry L. Increased gender-based violence among women internally displaced in Mississippi 2 years post-Hurricane Katrina. Disaster Med Public Health Preparedness. 2009;3:18-26.

2. Keenan HT, Marshall SW, Nocera MA, et al. Increased incidence of 
inflicted traumatic brain injury in children after a natural disaster. Am J Prev Med. 2004;26:189-193.

3. Curtis T, Miller BC, Berry EH, et al. Changes in reports and incidence of child abuse following natural disasters. Child Abuse Negl. 2000;24: $1151-1162$.

4. Johnson K. Association of combatant status and sexual violence with health and mental health outcomes in post-conflict Liberia. JAMA. 2008;300:676-690.

5. Sheldon T. Shining a light on suffering. BMJ. 2005;331:70.

6. Amowitz LL, Reis C, Lyons KH, et al. Prevalence of war-related sexual violence and other human rights abuses among internally displaced persons in Sierra Leone. JAMA. 2002;287:513-521.

7. Amaratunga C. Editorial comments-disasters, women's health, and conservative society: working in Pakistan with the Turkish Red Crescent following the earthquake in Southeast Asia. Prehosp Disaster Med. 2007;22:274-275.

8. Pittaway E, Bartolomei L, Rees S. Neglected issues and voices. Asia Pac J Public Health. 2007;19:69.

9. Miller AC, Arquilla B. Disasters, women's health, and conservative society: working in Pakistan with the Turkish Red Crescent following the South Asian Earthquake. Prehosp Disaster Med. 2007;22:269-275.

10. Turner H. Literature review: Afghanistan women's health crisis, health service delivery, and ethical issues for international aid. Health Care Women Int. 2006;27:748-759.

11. MacDonald R. How women were affected by the tsunami: a perspective from Oxfam. PLoS Med. 2005;2:e178.

12. Frasier PY, Belton L, Hooten E, et al. Disaster down east: using participatory action research to explore intimate partner violence in eastern North Carolina. Health Educ Behav. 2004;31 (Suppl 4):69S-84S.

13. Khawaja M, Barazi R. Prevalence of wife beating in Jordanian refugee camps: reports by men and women. J Epidemiol Community Health. 2005;59:840-841.
14. Enarson E. Through women's eyes: a gendered research agenda for disaster social science. Disasters. 1998;22:157-173.

15. Hynes M, Ward J, Robertson K, et al. A determination of the prevalence of gender-based violence among conflict-affected populations in East Timor. Disasters. 2004;28:294-321.

16. Ellsberg M, Heise L, Peña R, et al. Researching domestic violence against women: methodological and ethical considerations. Stud Fam Plann. 2001;32:1-16.

17. Garcia-Moreno C, Jansen HA, Ellsberg M, et al. WHO Multi-country Study on Women's Health and Domestic Violence Against Women Study Team. World Health Organization. Geneva: WHO Press; 2005:4-5.

18. Koss MP. Detecting the scope of rape: a review of prevalence research methods. J Interpers Violence. 1993;8:198-222.

19. Greenough PG, Lappi MD, Hsu EB, et al. Burden of disease and health status among Hurricane Katrina-displaced persons in shelters: a population-based cluster sample. Ann Emerg Med. 2008;51:426-432.

20. Tjaden P, Thoennes N. Prevalence, Incidence, and Consequences of Violence Against Women: Findings From the National Violence Against Women Survey. National Institute of Justice Web site with Centers for Disease Control and Prevention. http://www.ncjrs.gov/txtfiles/ 172837.txt. Accessed December 18, 2008.

21. Federal Bureau of Investigation. Crime in the United States, 2004: Uniform Crime Reports. Washington, DC: Department of Justice; 2005.

22. Larrance R, Anastario M, Lawry L. Health status among internally displaced persons in Louisiana and Mississippi travel trailer parks. Ann Emerg Med. 2007;49:590-601.

23. Intimate Partner Violence Prevalence Report in Nevada 2005-2006. Nevada Center for Health Statistics and Informatics Web site. http:// 74.125.95.132/search?q= cache:uO_Be9xsCp0J:hhs.unr.edu/nchsi/docs/nv_ partner_violence_05-06.pdf + brfss + Louisiana $+I P V+$ ModuleEghl=enE $c t=$ $c l n k \mathcal{E} c d=4 \mathcal{E} g l=u s$. Accessed November 22, 2008. 